\title{
Dynamics of Plasmodium falciparium and Plasmodium vivax in a micro-ecological setting, Southwest Ethiopia: effects of altitude and proximity to a dam
}

Lelisa Sena ${ }^{1,2^{*}}$, Wakgari Deressa ${ }^{2}$ and Ahmed Ali $^{2}$

\begin{abstract}
Background: Refining the spatial and temporal data on malaria transmissions at a defined ecological setting has practical implications for targeted malaria control and enhancing efficient allocation of resources. Spatial and temporal distribution of $P$. falciparium and $P$. vivax were explored around the Gilgel Gibe Hydroelectric Dam (GGHD) in southwest Ethiopia.

Methods: A review of confirmed malaria episodes recorded over eight years at primary health services was conducted. Using individual identifiers and village names malaria records were cross-linked to location and individual records of Gilgel Gibe Health and Demographic Surveillance System (HDSS) data, which had already been geo-referenced. The study setting was categorized in to buffer zones with distance interval of one kilometer. Similarly, altitude of the area was categorized considering 100 meters height intervals. Incidence rate ratios were estimated using Poisson model for the buffer zones and for the altitudinal levels by adjusting for the underlying population density as an offset variable. Yearly temporal variations of all confirmed malaria cases were also evaluated based on the Poisson model using STATA statistical software version 12.
\end{abstract}

Results: A considerable proportion (45.0\%) of the $P$. falciparium episodes were registered within one kilometer radius of the GGHD. P. falciparium showed increment with distance from the GGHD up to five kilometers and with altitude above 1900 meters while $P$. vivax exhibited the increase with distance but, decrease with the altitude. Both species showed significantly higher infection among males than females $(P<0.01)$. Temporally, malaria episodes manifested significant increments in the years between 2006/7 to 2009/10 while reduction of the malaria episodes was indicated during 2004/5, 2005/6 and 2010/11 compared to 2003/4 ( $P<0.01$ ). On average, $P$. vivax was 52\% less than $P$. falciparium over the time period considered. P. vivax was significantly higher in the years 2004/5 to 2007/8 and 2010/11 (P <0.001).

Conclusions: Spatial and temporal variations of malaria were observed. The spatial and temporal variations of malaria episodes were also different for the two main malaria species in the area.

Keywords: Ethiopia, Gilgel Gibe, Malaria episodes, Spatiotemporal dynamics

\footnotetext{
* Correspondence: lelisajitu@gmail.com

'Department of Epidemiology, College of Public Health and Medical Sciences, Jimma University, Jimma, Ethiopia

${ }^{2}$ Department of Preventive Medicine, School of Public Health, College of Health Sciences, Addis Ababa University, Addis Ababa, Ethiopia
} 


\section{Background}

The level of malaria occurrence is determined by the interactions between Plasmodium parasite, the Anopheles mosquito vector and the human host. The cycle of interactions, and consequently, the malaria transmission dynamics is determined by the ecological niche even in a small geographical area [1,2]. Hence, anthropogenic interference of the physical environment inevitably modifies the existing equilibrium cycle of the disease transmission pattern [3]. Since malaria transmission intensity varies geographically, the distribution of cases and subsequent morbidity rate may exhibit systematic spatial variation [4]. Therefore, the need for understanding spatial heterogeneity and temporal variations of malaria at micro- geographic level has been emphasized [5-7] for targeted control measure applications.

Currently, Ethiopia is undertaking construction of large hydroelectric dams $[8,9]$ and irrigation schemes of different scales [10-12] as part of developmental activities. This in turn can have impact on vector borne diseases, including malaria as the result of environmental modification. Due to human imposed environmental modifications, risk of malaria has been predicted to increase in East Africa $[13,14]$; on the other hand, well designed water projects are taught to economically benefit the residents of the dams vicinity and enable the community to strengthen the disease control programmes to overcome the adverse health effects $[15,16]$. However, the extent of health impact of hydroelectric dams on local communities closer to such dams is less studied.

A couple of local studies indicated increased risks on malaria were associated with proximity to water development schemes [17-19] all those studies were of crosssectional nature in design to capture temporal influence. However, a follow up study on children two to nine years reported that risk of malaria infection due to proximity to hydro-power dam was insignificant [20]. Still, a few other longitudinal studies [21,22] reported presence of malaria hot spots and heterogeneity of the disease at some relatively wider intervals. Altitudinal rise of the disease has been reported by some studies [23,24], though not reported usually by species. Moreover, studies done elsewhere [25-27] reported that proximity to water sources was not found to be risk factor for malaria, but other factors.

Hence, identification of those at risk areas and seasons provides strategies for targeting timely and locally tailored interventions [28,29]. Quantitative description of the spatiotemporal dynamics has practical implications for the development of malaria control and efficient allocation of resources [30,31]. Spatial investigation of geographic limits of transmission is also used to develop a predictive spatial model of malaria transmission, to facilitate a malaria control strategy based on geographic stratification [32]. To quantify the contribution made by operational intervention and effect of environmental factors, a clear knowledge about the dynamics of malaria in a particular area is important to plan better prevention and management strategies [33]. Therefore, this study was conducted to examine the role of proximity to a hydroelectric dam and altitude on the spatial distribution of $P$. falciparium and $P$. vivax.

\section{Methods \\ Study setting}

This record review was conducted in an area surrounding a man-made lake, Gilgel Gibe Hydroelectric Dam (GGHD), which has been operational since 2004 [34]. The area is a Health and Demographic Surveillance Site (HDSS) [35] which includes surrounding villages within ten $\mathrm{km}$ radius of the GGHD with about 50,000 residents used to live in the villages. The area is found within altitude range which favors seasonal malaria transmission [17,20]. Detailed descriptions of the study setting have also been given elsewhere $[17,36,37]$.

\section{Study design}

A retrospective record review study was employed using data from local health services (health centers and health posts). This was done by reviewing malaria morbidity records of local health facilities in villages included into the Gilgel Gibe HDSS. Using individual identifiers (name, age, and sex) and village names, malaria positive cases were cross-linked by careful inspection to location and individual records of the HDSS data which had already been geo-referenced (each house in the HDSS has geographic information system (GPS) records).

\section{Source of data}

In Ethiopia, malaria cases are treated both clinically and as confirmed malaria in accordance with the National Guideline [38,39], depending on the degree of diagnostic capabilities at different levels of the healthcare system. Both the presumptive and confirmed cases are registered on preformatted registration books (log books) at health care levels and reported both weekly as well as monthly to the next higher level of health management system. The current study included all malaria positive records of the local primary healthcare units that were within the Gilgel Gibe DHSS villages, registered by the primary health care units between September 2003 and August 2011 was reviewed. The timeline consideration was based on data availability and the fact that significant change in the number of malaria cases, such as epidemics, occurs in cyclic fashion from five to eight-year periods in the country [40-42], in order that any fluctuation of such cycle could be captured.

\section{Data collection techniques}

A format was prepared on a computer spreadsheet (Excel) to collect the secondary data from log books of 
local government primary health care units. Individual level data on malaria morbidity; such as, diagnosis results (negative, species of Plasmodium for positives); dates of diagnoses; available demographic data (residence, age, sex) were registered on the computer spreadsheet. All records of malaria cases who visited the health institutions during the designated time were included in the study. Records of cases with incomplete records, such as dates of health service visit, age, address, results of diagnosis, were excluded from the analysis. Furthermore, cases whose names, sex and age did not relate to the geo-referenced data of the Gilgel Gibe HDSS were excluded from the spatial analysis. Accordingly, a total of 10,443 records of malaria positive cases were linked to the geo-referenced HDSS data, which has data on household member list with individual, household and location identities (IDs) as well as GPS readings.

\section{Data management and processing}

The data on malaria positive records of the healthcare institutions of the study site were transferred to Excel spreadsheet, checked for completeness (date of diagnosis, test results, patient age and address), coded; then, prepared data of malaria cases were exported to STATA statistical software version 12. Episodes of malaria were considered instead of number of cases for the analysis. The study setting was categorized in to five buffer zones considering distance interval of one kilometer. The altitude of the area was also categorized into six levels as up to 1700,1701 to 1800, 1801 to 1900,1901 to 2000, 2001 to 2100 , and above 2100 meter above sea level (masl) taking into account the narrow range of this micro-epidemiological setting.

Incidence rate ratio (IRR), which is equivalent to odds ratio in the Poison regression, was estimated using Discrete Poisson model for the buffer zones and for the altitudinal levels. The numbers of base population in the buffer zones and in the ranges of altitude were incorporated as an offset variable to adjust for the underlying population density while computing the IRRs among both the buffer zones and ranges of the altitude. Furthermore, the inter-annual trend of the malaria episodes over the study years considered was analyzed both for all positive cases and for $P$. vivax malaria relative to P. falciparium using the IRR to detect change in magnitude of the malaria episodes by years relative to the initial year.

\section{Ethical considerations}

Ethical clearances were obtained from the Addis Ababa University College of Health Sciences Ethical Review Board and Oromia Regional Health Bureau Ethical Clearance Committee. Jimma Zone Health Office and the respective District Health offices of the study areas as well as local administrators were communicated by formal letters written from the School of Public Health of the Addis Ababa University and Oromia Regional Health Bureau. Individual information was kept confidential and the names of individuals were removed from data and identified only by identification numbers and the results were communicated in an aggregated manner.

\section{Results}

A total of 53,624 malaria episodes were recorded in the Gilgel Gibe HDSS site over a period of eight years of which 25,605 (47.7\%) were records of clinical malaria and 28,019 (52.3\%) were confirmed malaria episodes. Of the positive cases, P. falciparium, P. vivax and mixed species constituted $60.4 \%, 33.6 \%$ and $6.0 \%$ respectively. Only those records managed to be linked with location identification of the Gilgel Gibe HDSS (10,443 episode records) were analyzed for spatial distribution of the diseases (Table 1) while all the confirmed positive malaria records were considered in the temporal analysis.

The species composition of the geo-referenced malaria episodes were $P$. falciparium (69.2\%), P. vivax (22.6\%) and mixed species (8.2). Generally, the contribution of $P$. falciparium was higher near the GGHD and proportion of $P$. vivax exhibited increment with distance from the GGHD. Overall, $38.4 \%$ of the episodes were recorded in a distance of less than one kilometer radius of GGHD of which P. falciparium and P. vivax accounted $81.0 \%$ and $10.0 \%$ respectively. In the buffer zone one to two kilometer radius of the GGHD, where about a quarter of the malaria episodes were recorded, $P$. falciparium contributed $68.2 \%$ while the proportion of $P$. vivax was $22.5 \%$. In the buffer zone from two to three kilometers radius P. falciparium and P. vivax accounted for $62.7 \%$ and $27.8 \%$ respectively. The proportions of $P$. falciparium in the buffer zones from three to four and four to five kilometers were $58.9 \%$ and $47.6 \%$ while that of $P$. vivax were $34.8 \%$ and $48.3 \%$ respectively. Beyond five kilometers, the proportion of $P$. falciparium showed sharp decline to $7.3 \%$ while that of $P$. vivax rose to $91.8 \%$.

Distribution of malaria episodes showed different patterns within species as well among the buffer zones. Unlike to $P$. vivax (18.1\%), $46.4 \%$ of the P. falciparium and $39.4 \%$ of mixed species episodes were registered within one kilometer radius of the GGHD.

The proportions of $P$. falciparium and $P$. vivax recorded in the buffer zone range from one to two and two to three kilometers radius of GGHD were similar, which were $26.5 \%$ and $14.8 \%$ for P. falciparium and $26.7 \%$ and $20.0 \%$ for $P$. vivax respectively. On the other hand, only less than four in ten $(3.6 \%)$ cases of $P$. falciparium but recognizable proportion (19.5\%) of the P. vivax episodes were recorded beyond three kilometers radius of the GGHD.

Only less than $0.9 \%$ of the malaria episodes were registered to occur in the lower altitude of up to 1700 meter above sea level (masl). Majority (79.2\%) of the malaria episodes were registered in the altitude range 
Table 1 Distribution of malaria cases by sex, distance from GGHD, altitude and Plasmodium species, southwest Ethiopia, September 2003 to August 2011

\begin{tabular}{|c|c|c|c|c|c|}
\hline \multirow[t]{2}{*}{ Variables } & \multirow[t]{2}{*}{ Categories } & \multicolumn{3}{|c|}{ Diagnosis (species of Plasmodium), N (\%*) } & \multirow[t]{2}{*}{ Total } \\
\hline & & P. falciparium & P. vivax & Mixed & \\
\hline \multirow[t]{6}{*}{ Distance } & $<1 \mathrm{~km}$ & $3,250(45.0)$ & $427(18.1)$ & $336(39.3)$ & $4,013(38.4)$ \\
\hline & 1 to $2 \mathrm{~km}$ & $1,890(26.2)$ & $629(26.6)$ & $261(30.5)$ & $2,780(26.6)$ \\
\hline & 2 to $3 \mathrm{~km}$ & $1,180(16.3)$ & $473(20.0)$ & $167(19.5)$ & $1,820(17.4)$ \\
\hline & 3 to $4 \mathrm{~km}$ & $661(9.2)$ & $395(16.7)$ & $68(8.0)$ & $1,124(10.8)$ \\
\hline & 4 to $5 \mathrm{~km}$ & $243(3.4)$ & $228(9.7)$ & $21(2.5)$ & $492(4.7)$ \\
\hline & $>5 \mathrm{~km}$ & $2(0.03)$ & $210(8.9)$ & $2(0.2)$ & $214(2.1)$ \\
\hline \multirow[t]{6}{*}{ Altitude } & $\leq 1700 \mathrm{~m}$ & $18(0.3)$ & $74(3.1)$ & $5(0.6)$ & $97(0.9)$ \\
\hline & $1701-1800 \mathrm{~m}$ & $5,796(80.2)$ & $1,755(74.3)$ & $716(83.7)$ & $8,267(79.2)$ \\
\hline & $1801-1900 \mathrm{~m}$ & 857 (11.9) & $348(14.7)$ & $77(9.0)$ & $1,282(12.3)$ \\
\hline & $1901-2000 \mathrm{~m}$ & $302(4.2)$ & $115(4.9)$ & $37(4.3)$ & $454(4.4)$ \\
\hline & $2001-2100 \mathrm{~m}$ & $137(1.9)$ & $35(1.5)$ & $15(1.8)$ & $187(1.8)$ \\
\hline & $>2100 \mathrm{~m}$ & 116 (1.6) & $35(1.5)$ & $5(0.6)$ & $156(1.5)$ \\
\hline \multirow[t]{4}{*}{ Age (year) } & $<5$ & $651(9.0)$ & $258(10.9)$ & $85(9.9)$ & 994 (9.5) \\
\hline & $5-9$ & $968(13.4)$ & 345 (14.6) & $114(13.3)$ & $1,427(13.7)$ \\
\hline & $10-14$ & 1,098 (15.2) & $370(15.7)$ & 116 (13.6) & $1,584(15.2)$ \\
\hline & $15+$ & $4,509(62.4)$ & $1,389(58.8)$ & $540(63.2)$ & $6,438(61.7)$ \\
\hline \multirow[t]{2}{*}{ Sex } & Male & 4,032 (55.8) & $1,360(57.6)$ & $450(52.8)$ & $5,842(56.0)$ \\
\hline & Female & $3,194(44.2)$ & $1,002(42.4)$ & $404(57.2)$ & $4,600(44.1)$ \\
\hline \multirow[t]{2}{*}{ Total } & & $7,226(100)$ & $2,362(100)$ & $855(100)$ & $10,443(100)$ \\
\hline & & 69.2 & 22.6 & 8.2 & 100 \\
\hline
\end{tabular}

*Percentage within diagnosis.

from $1701-1800$ masl where $80.2 \%$ of the $P$. falciparium and $74.3 \%$ of $P$. vivax malaria episodes were recorded and the composition of $P$. falciparium and $P$. vivax were $70.1 \%$ and $21.2 \%$ respectively. The next larger number (12.3\%) of malaria episodes was registered in the altitude range from 1801-1900 masl. In this altitude range, 11.9\% and $14.3 \%$ P. falciparium and P. vivax were recorded and the proportions contributed by $P$. falciparium and $P$. vivax were $66.9 \%$ and $27.2 \%$ respectively (Table 1 ).

As distance increases from the GGHD, the occurrence of $P$. falciparium malaria increases significantly up to five kilometers $(\mathrm{P}<0.001)$, controlling the effects of altitude, age and gender (Table 2). The P. falciparium malaria was 3.8, 5.1, 3.7 and about 3 times more likely to occur in the buffer zones from one to two $\mathrm{km}$, two to three $\mathrm{km}$, three to four $\mathrm{km}$ and four to five $\mathrm{km}$ respectively compared to the occurrence of $P$. falciparium malaria within one $\mathrm{km}$ buffer zone of the GGHD.

Increasing altitude showed negative correlation with the occurrence of $P$. falciparium malaria up to 1900 masl, but it exhibited positive association as altitude increases above 1900 masl and the correlation was significant $(\mathrm{P}<0.01)$. Altitudes in the range of 1901-2000 m, 2001-2100 and above 2100 were $1.6,2.5$ and 2.6 times more likely to increase the risk of $P$. falciparium malaria compared to altitude up to 1700 masl. Regarding to the risk of $P$. falciparium infection among different age groups, children in the age range ten to fourteen years were affected more significantly than the other age groups $(\mathrm{P}=0.04)$. The risk of $P$. falciparium malaria was seen to be significantly higher among males than females $(\mathrm{P}<0.01)$ when the effects of distance from the GGHD, altitude and age are controlled (Table 2).

On the other hand, as distance from the GGHD increases, the occurrence of $P$. vivax malaria increases consistently and significantly $(\mathrm{P}<0.001)$, keeping the effects of altitude and gender constant. The occurrence of malaria in the buffer zones from one to two $\mathrm{km}$, two to three $\mathrm{km}$, three to four $\mathrm{km}$, four to five $\mathrm{km}$ and beyond five $\mathrm{km}$ was 9.8 times, 13.6 times, 11.9 times, 52.0 times and 68.7 times more likely to occur compared to the occurrence of $P$. vivax malaria in the buffer zone within one $\mathrm{km}$ radius of the GGHD. However, increasing altitude was negatively and significantly associated with the occurrence of $P$. vivax malaria $(\mathrm{P}<0.001)$.

Children under the age of five years were found to be more affected by $P$. vivax malaria than the other age categories. The risk of $P$. vivax among children five to nine 
Table 2 Effects of proximity to a dam and altitude on Plasmodium falciparium malaria southwest Ethiopia, September 2003 to August 2011

\begin{tabular}{|c|c|c|c|c|c|c|}
\hline \multirow[t]{2}{*}{ Variables } & \multirow[t]{2}{*}{ Categories } & \multirow[t]{2}{*}{ IRR } & \multirow[t]{2}{*}{ Std. Err. } & \multirow[t]{2}{*}{$P$ Value } & \multicolumn{2}{|c|}{ 95\% C.I. } \\
\hline & & & & & Lower & Upper \\
\hline \multirow[t]{6}{*}{ Buffer zones relative to GGHD } & $<1 \mathrm{~km}$ & 1 & & & & \\
\hline & $1-2 \mathrm{~km}$ & 3.82 & 0.07 & $<0.001$ & 3.68 & 3.96 \\
\hline & $2-3 \mathrm{~km}$ & 5.10 & 0.12 & $<0.001$ & 4.88 & 5.34 \\
\hline & $3-4 \mathrm{~km}$ & 3.73 & 0.10 & $<0.001$ & 3.53 & 3.93 \\
\hline & $4-5 \mathrm{~km}$ & 2.97 & 0.13 & $<0.001$ & 2.72 & 3.24 \\
\hline & $>5 \mathrm{~km}$ & 1.04 & 0.15 & 0.81 & 0.78 & 1.37 \\
\hline \multirow[t]{6}{*}{ Altitude in meters } & $\leq 1700$ & 1 & & & & \\
\hline & $1701-1800$ & 0.03 & 0.01 & $<0.001$ & 0.02 & 0.04 \\
\hline & $1801-1900$ & 0.93 & 0.17 & 0.71 & 0.65 & 1.33 \\
\hline & $1901-2000$ & 1.61 & 0.30 & 0.01 & 1.12 & 2.31 \\
\hline & $2001-2100$ & 2.51 & 0.47 & $<0.001$ & 1.74 & 3.63 \\
\hline & $2101-2230$ & 2.64 & 0.50 & $<0.001$ & 1.82 & 3.82 \\
\hline \multirow[t]{4}{*}{ Age (year) } & $<5$ & 1 & & & & \\
\hline & $5-9$ & 1.05 & 0.04 & 0.19 & 0.98 & 1.12 \\
\hline & $10-14$ & 1.10 & 0.04 & $<0.01$ & 1.03 & 1.17 \\
\hline & $15+$ & 1.04 & 0.03 & 0.14 & 0.99 & 1.10 \\
\hline \multirow[t]{2}{*}{ Sex } & Male & 1 & & & & \\
\hline & Female & 0.96 & 0.01 & 0.01 & 0.93 & 0.99 \\
\hline
\end{tabular}

years, ten to fourteen years and adult age groups was less by about $9 \%, 16 \%$ and $11 \%$ respectively compared to the risk of $P$. vivax in the under five years of age children. There was also higher chance of $P$. vivax malaria risk among males compared to females keeping the effects of altitude, distance from GGHD and age constant (Table 3).

Overall, there was reduction of about $70 \%$ and $60 \%$ of malaria episodes in the years 2004/5 and 2005/6 respectively compared to that of $2003 / 4$. However, since $2006 / 7$ increment of malaria episodes was evident up to 2010. In $2006 / 7$ the malaria episode increased about $14.9 \%$ as compared to $2003 / 4$. In the following three years, the increment of malaria episodes was 2.3 times, 2.9 times and 4.1 times more likely higher in the years 2008/9, 2009/10 and 2011 as compared to the observed episodes of malaria in the year 2003/4. In the year 2011, the malaria episodes showed reduction of $14 \%$ which was statistically insignificant $(\mathrm{P}=0.30)$.

On average, $P$. vivax was $52 \%$ lower than $P$. falciparium over the study period considered. The rate of $P$. vivax increments were $130 \%$ and $40 \%$ in the years $2004 / 5$ and 2005/6 respectively as compared to $P$. falciparium episodes those years. In the years 2006/7, 2007/8 and 2010/ 2011 there were $60 \%$ P. vivax rate increments compared to $P$. falciparium during the same time. On the other hand, in the years 2008/9 and 2009/10, there were reductions of P. vivax episodes rate by $10 \%$ and $16 \%$ respectively though the reduction was insignificant in 2008/9 $(P=0.06)$ (Table 4).

\section{Discussions}

This study assessed malaria transmission intensity level spatially within the proximity of GGHD taking into account possible influence of altitude on episodes of $P$. falciparium and P. vivax malaria. Temporal trend of all positive episodes of malaria over an eight year period was also examined.

There was variation of species with respect to distance from the GGHD and altitudinal levels. From descriptive analysis, it was apparent that most of $P$. falciparium malaria have occurred nearer to the Dam, within two kilometer radius of GGHD and showed reduction with distance from Dam. This finding is in line with previous local studies $[18,43,44]$ though the earlier findings were not reported in terms of plasmodium species composition. However, adjusting for the population density revealed the risk of $P$. falciparium infection was higher beyond one $\mathrm{km}$ radius of the Dam, especially in the buffer zone two to three $\mathrm{km}$ of the Dam.

The spatial cluster of $P$. falciparium in a small geographical area is also compatible with other findings $[1,22,45,46]$. However, the current finding is in contrast to previous local findings, where the risk difference for $P$. falciparium between children who lived within three kilometer of GGHD and beyond eight kilometers was insignificant 
Table 3 Effects of proximity to a dam and altitude on Plasmodium vivax malaria southwest Ethiopia, September 2003 to August 2011

\begin{tabular}{|c|c|c|c|c|c|c|}
\hline \multirow[t]{2}{*}{ Variables } & \multirow[t]{2}{*}{ Categories } & \multirow[t]{2}{*}{ IRR of $P v$} & \multirow[t]{2}{*}{ Std. Err. } & \multirow[t]{2}{*}{ P Value } & \multicolumn{2}{|c|}{ 95\% C.I. } \\
\hline & & & & & Lower & Upper \\
\hline \multirow[t]{6}{*}{ Buffer zones relative to GGHD } & $<1 \mathrm{~km}$ & 1 & & & & \\
\hline & $1-2 \mathrm{~km}$ & 9.82 & 0.32 & $<0.001$ & 9.22 & 10.47 \\
\hline & $2-3 \mathrm{~km}$ & 13.56 & 0.50 & $<0.001$ & 12.61 & 14.58 \\
\hline & $3-4 \mathrm{~km}$ & 11.94 & 0.49 & $<0.001$ & 11.02 & 12.93 \\
\hline & $4-5 \mathrm{~km}$ & 52.00 & 2.10 & $<0.001$ & 48.03 & 56.29 \\
\hline & $>5 \mathrm{~km}$ & 68.72 & 3.46 & $<0.001$ & 62.26 & 75.85 \\
\hline \multirow[t]{6}{*}{ Altitude in meters } & $\leq 1700 \mathrm{~m}$ & 1 & & & & \\
\hline & $1701-1800$ & 0.02 & 0.001 & $<0.001$ & 0.02 & 0.01 \\
\hline & $1801-1900$ & 0.44 & 0.03 & $<0.001$ & 0.38 & 0.50 \\
\hline & $1901-2000$ & 0.64 & 0.05 & $<0.001$ & 0.55 & 0.75 \\
\hline & $2001-2100$ & 0.51 & 0.06 & $<0.001$ & 0.41 & 0.64 \\
\hline & $>2100 \mathrm{~m}$ & 0.54 & 0.06 & $<0.001$ & 0.43 & 0.68 \\
\hline \multirow[t]{4}{*}{ Age (year) } & $<5$ & 1 & & & & \\
\hline & $5-9$ & 0.91 & 0.04 & 0.03 & 0.83 & 0.99 \\
\hline & $10-14$ & 0.84 & 0.04 & $<0.001$ & 0.78 & 0.92 \\
\hline & $15+$ & 0.89 & 0.03 & 0.001 & 0.83 & 0.95 \\
\hline \multirow[t]{2}{*}{ Sex } & Male & 1 & & & & \\
\hline & Female & 1.04 & 0.02 & 0.04 & 1.00 & 1.09 \\
\hline
\end{tabular}

Table 4 Trends of confirmed malaria by year and Species southwest Ethiopia, September 2003 to August 2011

\begin{tabular}{|c|c|c|c|c|c|c|}
\hline \multirow{2}{*}{$\begin{array}{l}\text { Plasmodium species } \\
\text { All positive }\end{array}$} & \multirow{2}{*}{$\begin{array}{l}\text { Year } \\
2003 / 4\end{array}$} & \multirow{2}{*}{$\begin{array}{l}\text { IRR } \\
1\end{array}$} & \multirow[t]{2}{*}{ Std. Err. } & \multirow[t]{2}{*}{$P$ value } & \multicolumn{2}{|c|}{ (95\% C. I.) } \\
\hline & & & & & & \\
\hline & $2004 / 5$ & 0.30 & 0.02 & $<0.001$ & 0.27 & 0.34 \\
\hline & $2005 / 6$ & 0.40 & 0.02 & $<0.001$ & 0.36 & 0.44 \\
\hline & $2006 / 7$ & 1.15 & 0.04 & $<0.001$ & 1.07 & 1.24 \\
\hline & $2007 / 8$ & 2.26 & 0.08 & $<0.001$ & 2.11 & 2.41 \\
\hline & $2008 / 9$ & 2.87 & 0.09 & $<0.001$ & 3.00 & 3.06 \\
\hline & 2009/10 & 4.08 & 0.13 & $<0.001$ & 3.84 & 4.34 \\
\hline & 2010/11 & 0.96 & 0.04 & 0.30 & 0.89 & 1.04 \\
\hline \multirow[t]{2}{*}{$P$. vivax in reference to $P$. falciparium } & During the whole period & 1 & & & & \\
\hline & & 0.48 & 0.02 & $<0.001$ & 0.43 & 0.52 \\
\hline Rate ratio & $2003 / 4$ & 1 & & & & \\
\hline P. vivax to & $2004 / 5$ & 2.30 & 0.20 & $<0.001$ & 1.95 & 2.72 \\
\hline \multirow[t]{6}{*}{ P. falciparium } & $2005 / 6$ & 1.41 & 0.12 & $<0.001$ & 1.19 & 1.67 \\
\hline & $2006 / 7$ & 1.57 & 0.10 & $<0.001$ & 1.39 & 1.78 \\
\hline & $2007 / 8$ & 1.59 & 0.09 & $<0.001$ & 1.42 & 1.77 \\
\hline & $2008 / 9$ & 0.90 & 0.05 & 0.06 & 0.80 & 1.00 \\
\hline & 2009/10 & 0.84 & 0.05 & $<0.01$ & 0.76 & 0.94 \\
\hline & 2010/11 & 1.61 & 0.10 & $<0.001$ & 1.42 & 1.83 \\
\hline
\end{tabular}


$[17,20]$, implying proximity to water bodies alone does not increase risk of the disease. Again, another study reported that distance to water body was reported not to be significantly associated with prevalence of $P$. falciparium malaria [26].

However, the magnitude of $P$. falciparium malaria exhibited increment with altitude above 1900 masl, implying the up scrolling of malaria to highland areas possibly due to change in climate variables as had already been evidenced elsewhere $[14,24]$. The fact that $P$. falciparium prevails in the area mainly for short period of time following heavy rainfall from September to November usually in the form of epidemics [47], might have played a role in increasing the number of cases with altitude, as more susceptible individuals are exposed to the infection for relatively shorter duration due to the wave of epidemics.

On the other hand, P. vivax malaria episodes exhibited decrease as altitude increased, especially starting from 1800 masl; however, it showed persistently significant increase as distance increases from GGHD ( $\mathrm{P}<0.001)$. The decrement of $P$. vivax malaria episodes with increasing altitude was similar to another finding [48]. The proportional increment of $P$. vivax malaria episodes with the distance from the Dam was in agreement with a previous local study which indicated that, unlike $P$. falciparium malaria, more $P$. vivax malaria among distant communities was comparable to those close to a large dam [9]; however, the underlying rationale is not clear and needs further explorations as the $P$. vivax has been given less attention and under studied [49] in spite of the fact that it poses potential severe health consequences [50-52].

Pertaining to the trend of the disease, $P$. falciparium malaria significantly increased from 2006/7 to 2009/10 ( $\mathrm{P}<0.001$ ), compared to the $2003 / 4$, but it was lower in the years 2004/5, 2005/6 and 2010/11. Such persistent increment of the episodes of $P$. falciparium could possibly be due to resistance development by malaria vector mosquitoes to insecticides that had been in use for indoor residual spraying (IRS) in the country for about half of a century until vector resistance to DDT was detected in 2007 [53-55]. The noticed decline of P. falciparium malaria episodes after 2010 could possibly be due to the replacement of old LLINs in 2009, and shifting of insecticide used for IRS in 2010 to deltamethrin or bendiocarb insecticides [53], such coincidence of interventions followed by a sharp drop of malaria episodes, had also been reported by other studies [56-61] whereas weakened interventions and development of resistances of the vector to insecticides and the parasite to drugs have been documented to associate with the resurgence of the diseases [62].

The decline of $P$. falciparium malaria episodes between 2004/5 and 2005/6 might also be attributed to the scale up of interventions, including LLITNs [63,64] following the large scale malaria epidemics of 2003 [65,66] implying the need for monitoring the major malaria intervention tools such as IRS \& LLITNs, the effectiveness.

\section{Conclusions}

There were both temporal and spatial variations of malaria episodes during the study period. The rise of malaria episodes between the years 2008 and 2010 was due to $P$. falciparium where the contribution of $P$. vivax especially during 2009 and 2010 was lower compared to 2003/4. Spatial distribution of the two species was different that though both exhibited increase with distance from the Dam, $P$. vivax episodes increased by many folds constantly as distance increases from the Dam. However, $P$. vivax episodes were limited mainly to relatively lower altitude range. Regarding to the increment of $P$. falciparium with altitude and that of $P$. vivax with distance from reservoir of dams, further exploration is needed.

Given the higher proportion of $P$. falciparium that contributed to about two-third of the malaria episodes of the area, and the fact that still more than two-third of the $P$. falciparium occurred within two kilometers radius of the GGHD, it demands a vigilant monitoring of the disease in the area and sustainable interventions. Density of the base population needs to be considered while conducting spatial analysis of diseases, which is mostly overlooked.

\section{Competing interests}

The authors declare that they have no competing interests.

\section{Authors' contributions}

LS participated in the study design, undertook the field study, analyzed data and wrote the manuscript. WD participated in the study design, revision of the manuscript and facilitation of administrative issues. AA participated in the study design, revision of the manuscript and facilitation of administrative issues. All the authors have also read the manuscript and approved it to submit for publication.

\section{Acknowledgements}

We are grate to local health managers, data collectors and supervisors. Addis Ababa University is greatly acknowledged for funding the study.

Received: 26 June 2014 Accepted: 10 November 2014

Published online: 19 November 2014

\section{References}

1. Kasasa S, Asoala V, Gosoniu L, Anto F, Adjuik M, Tindana C, Smith T, Owusu Agyei S, Vounatsou P: Spatio-temporal malaria transmission patterns in Navrongo demographic surveillance site, northern Ghana. Malar J 2013, 12:63.

2. Craig MH: The Temporal and Spatial Distribution of Malaria in Africa, with Emphasis on Southern Africa. Durban: University of Basel; 2009.

3. Haque U, Sunahara T, Hashizume M, Shields T, Yamamoto T, Haque R, Glass GE: Malaria prevalence, risk factors and spatial distribution in a hilly forest area of Bangladesh. PLoS One 2011, 6(4):e18908. doi:18910.11371/ journal.pone.0018908.

4. Moffett A, Shackelford N, Sarkar S: Malaria in Africa: vector species' niche models andrelative risk maps. PLoS One 2007, 5(9):e824.

5. Wardrop NA, Barnett AG, Atkinson J-A, Clements AC: Plasmodium vivax malaria incidence over time and its association with temperature and rainfall in four counties of Yunnan Province, China. Malar J 2013, 12:452

6. Zhou G, Sirichaisinthop J, Sattabongkot J, Johnes J, Bjornstad O, Yan G, Cu L: Spatio-temporal distribution of plasmodium falciparium and $p$. Vivax malaria in Thailand. Am J Trop Med Hyg 2005, 72(3):256-262. 
7. Chowell G, Munayco CV, Escalante AA, McKenzie FE: The spatial and temporal patterns of falciparium and vivax malaria in Perú: 1994-2006. Malar J 2009, 9:42

8. Velleux JC: The human security dimensions of dam development: the grand Ethiopian renaissance dam. Global Dialogue 2013, 15(2):1-15

9. Lautze J, McCartney M, Kirshen P, Olana D, Jayasinghe G, Spielman A: Effect of a large dam on malaria risk: the Koka reservoir in Ethiopia. Trop Med Int Health 2007, 12(8):982-989.

10. Eguavoen I, Derib SD, Deneke T, McCartney M, Otto BA, Billa SS: Digging, damming or diverting? small-scale irrigation in the blue nile Basin. Ethiop Water Altern 2012, 5(3):678-699.

11. Belay S, Beyene F: Small-scale irrigation and household income linkage: Evidence from Deder district, Ethiopia. Afr J Agric Res 2013, 8(34):4441-4451.

12. Asayehegn K: Negative impact of small-scale irrigation schemes: A case study of Central Tigray regional state, Ethiopia. Agric Res Rev 2012, 1(3):80-85.

13. Ermert $\mathrm{V}$, Fink $\mathrm{AH}$, Paeth $\mathrm{H}$ : The potential effects of climate change on malaria transmission in Africa using bias-corrected regionalised climate projections and a simple malaria seasonality model. Clim Chang 2013, 120:741-754.

14. Peterson AT: Shifting suitability for malaria vectors across Africa with warming climates. BMC Infect Dis 2009, 9:59

15. Ersado L: Small-Scale Irrigation Dams, Agricultural Production, and Health: Theory and Evidence from Ethiopia. 1818 H St NW, MSN: H4-405, Washington, DC: World Bank Policy Research Working Paper 3494; 2005.

16. Tol RSJ: Infectious disease, development, and climate change: a scenario analysis. Environ Dev Econ 2007, 12:687-706.

17. Yewhalaw D, Legesse W, Bortel WV, Gebre-Selassie S, Kloos H, Duchateau L, Speybroeck N: Malaria and water resource development: the case of Gilgel-Gibe hydroelectric dam in Ethiopia. Malar J 2009, 8:21.

18. Ghebreyesus TA, Haile M, Witten KH, Getachew A, Ambachew M, Yohannes AM, Yohannes M, Teklehaimanot HD, Lindsay SW, Byass P: Incidence of malaria among children living near dams in northern Ethiopia: community based incidence survey. BMJ 1999, 319:663-666.

19. Kibret S, Alemu Y, Boelee E, Tekie H, Alemu D, Petros B: The impact of a small-scale irrigation scheme on malaria transmission in Ziway area, Central Ethiopia. Trop Med Int Health 2010, 15(1):41-50.

20. Yewhalaw D, Getachew Y, Tushune K, W/Michael K, Kassahun W, Duchateau $L$, Speybroeck N: The effect of dams and seasons on malaria incidence and anopheles abundance in Ethiopia. BMC Infect Dis 2013, 13:161.

21. Alemu K, Worku A, Berhane Y: Malaria infection has spatial, temporal, and spatiotemporal heterogeneity in unstable malaria transmission areas in Northwest Ethiopia. PLoS One 2013, 8(11):e79966.

22. Yeshiwondim AK, Gopal S, Hailemariam AT, Dengela DO, Patel HP: Spatial analysis of malaria incidence at the village level in areas with unstable transmission in Ethiopia. Int J Health Geogr 2009, 8:5

23. Siraj AS, Santos-Vega M, Bouma MJ, Yadeta D, Carrascal DR, Pascual M: Altitudinal changes in malaria incidence in highlands of Ethiopia and Colombia. Science 2014, 343:1154. 2014, 343:1155-1158.

24. Woyessa A, Gebre-Michael T, Ali A, Kebede D: Malaria in Addis Ababa and its environs: assessment of magnitude and distribution. Ethiop J Health Dev 2002, 16(2):147-155.

25. Haque U, Huda M, Hossain A, Ahmed SM, Moniruzzaman M, Haque R: Spatial malaria epidemiology in Bangladeshi highlands. Malar J 2009, 8:185.

26. Noor AMCA, Gething PW, Moloneys G, Boles M, Shewchuk T, Hay SI, Snow RW: Spatial prediction of Plasmodium falciparium prevalence in Somalia. Malar J 2008, 7:159. doi:10.1186/1475-2875-1187-1159.

27. Thomson MC, Connor SJ, D'alessandro U, Rowlingson B, Diggle P, Cresswell M, Greenwood B: Predicting malaria infection in Gambian children from satellite data and bed net use surveys: the importance of spatial correlation in the interpretation of results. Am Soc Trop Med Hyg 1999, 61(1):2-8.

28. Kamanga A, Moono P, Stresman G, Mharakurwa S, Shiff C: Rural health centres, communities and malaria case detection in Zambia using mobile telephones: a means to detect potential reservoirs of infection in unstable transmission conditions. Malar J 2010, 9:96.

29. Hui F-M, Xu B, Chen Z-W, Cheng X, Liang L, Huang H-B, Fang L-Q, Yang H, Zhou H-N, Yang H-L, Zhou X-N, Cao W-C, Gong P: Spatio-temporal distribution of malaria in Yunnan Province, China. Am J Trop Med Hyg 2009, 8(3):503-509.

30. Mabaso ML, Vounatsou P, Midzi S, Silva JD, Smith T: Spatio-temporal analysis of the role of climate in inter-annual variation of malaria incidence in Zimbabwe. Int J Health Geogr 2006, 5:20.
31. Hay SI, Guerra CA, Gething PW, Patil AP, Tatem AJ, Noor AM, Kabaria CW, Manh BH, Elyazar IRF, Brooker S, Smith DL, Moyeed RA, Snow RW: A world malaria map: Plasmodium falciparium endemicity in 2007. PLoS Med 2009, 6(3):e1000048.

32. Ostfeld RS, Glass GE, Keesing F: Spatial epidemiology: an emerging (or re-emerging) discipline. Trends Ecol Evol 2005, 20(6):328-336.

33. Kochar DKSP, Kochar SK, Budania MP, Lakhotia JP: Dynamics of malaria in Bikaner, Rajasthan, India (1975-2006). J Vector Borne Dis 2007, 44:281-284.

34. Yewhalaw D, Kassahun W, Woldemichael K, Tushune K, Sudaker M, Kaba D, Duchateau L, Bortel W, Speybroeck N: The influence of the Gilgel-Gibe hydroelectric dam in Ethiopia on caregivers' knowledge, perceptions and health-seeking behaviour towards childhood malaria. Malar J 2010, 9:47.

35. Deribew A, Alemseged F, Tessema F, Sena L, Birhanu Z, Zeynudin A, Sudhakar M, Abdo N, Deribe K, Biadgilign S: Malaria and under-nutrition: a community based study among under-five children at risk of malaria, south-west Ethiopia. PLOS One 2010, 5(5):e10775.

36. Deribew A, Alemseged F, Birhanu Z, Sena L, Tegegn A, Zeynudin A, Dejene T, Sudhakar M, Abdo N, Tessema F: Effect of training on the use of long-lasting insecticide-treated bed nets on the burden of malaria among vulnerable groups, south-west Ethiopia: baseline results of a cluster randomized trial. Malar J 2010, 9:121.

37. Deribew A, Birhanu Z, Sena L, Dejene T, Reda AA, Sudhakar M, Alemseged F, Tessema F, Zeynudin A, Biadgilign S, Deribe K: The effect of household heads training about the use of treated bed nets on the burden of malaria and anaemia in under-five children: a cluster randomized trial in Ethiopia. Malar J 2012, 11:8.

38. $\mathrm{MOH}$ : Malaria Diagnosis and Treatment Guidelines for Health Workers in Ethiopia 2nd Edition, Malaria and Other Vector-borne Diseases Prevention and Control Team Diseases Prevention and Control Department. Addis Ababa, Ethiopia: Ministry of Health; 2004.

39. $\mathrm{MOH}$ : National Malaria Guidelines. Addis Ababa: Ministry of Health; 2012.

40. $\mathrm{MOH}$ : Guideline for Malaria epidemic Prevention and Control in Ethiopia 2nd ed. Malaria and Other Vector-borne Diseases Prevention and Control Team. Addis Ababa, Ethiopia: Ministry of Health; 2004.

41. Teklehaimanot HD, Lipsitch M, Teklehaimanot A, Schwartz J: Weather-based prediction of Plasmodium falciparium malaria in epidemic-prone regions of Ethiopia I. Patterns of lagged weather effects reflect biological mechanisms. Malar J 2004, 3:41.

42. Deressa W, Olana D, Chibsa S: Community participation in malaria epidemic control in highland areas of southern Oromia, Ethiopia. Ethiop J Health Dev 2005, 19(1):3-10.

43. Peterson I, Borrell LN, El-Sadr W, Teklehaimanot A: A temporal-spatial analysis of malaria transmission in Adama, Ethiopia. Am J Trop Med Hyg 2009, 81(6):944-949.

44. Alemu G: Prevalence of Malaria and its influencing factors in Awassa District, Southern Ethiopia. Addis Ababa: Addis Ababa University; 2006

45. Bautista CT, Chan AS, Ryan JR, Calampa C, Roper CH, Hightower AW, Magill AJ: Epidemiology and spatial analysis of malaria in the northern Peruvian Amazon. Am J Trop Med Hyg 2006, 75(6):1216-1222.

46. Saxena R, Nagpal BN, Das MK, Srivastava A, Gupta SK, Anil Kumar ATJ, Baraik VK: A spatial statistical approach to analyze malaria situation at micro level for priority control in Ranchi district, Jharkhand. Indian J Med Res 2012, 136:776-782

47. Sena LD, Deressa WA, Ali AA: Analysis of trend of malaria prevalence: a retrospective comparative study, southwest Ethiopia. Malar J 2014, 13:188.

48. Woyessa A, Deressa W, Ali A, Lindtjørn B: Prevalence of malaria infection in Butajira area, south-central Ethiopia. Malar J 2012, 11:84.

49. Gething PW, Elyazar IRF, Moyes CL, Smith DL, Battle KE, Guerra CA, Patil AP, Tatem AJ, Howes RE, Myers MF, George DB, Horby P, Wertheim HFL, Price RN, Eller IM, Baird JK, Hay SI: A long neglected world malaria map: plasmodium vivax endemicity in 2010. PLoS Negl Trop Dis 2012, 6(9):e1814.

50. Fru-Cho J, Bumah W, Safeukui I, Nkuo-Akenji T, Titanji VP, Haldar K: Molecular typing reveals substantial Plasmodium vivax infection in asymptomatic adults in a rural area of Cameroon. Malar J 2014, 13:170.

51. Hyder Mahgoub GIG, Musa IR, Ishag A: Severe Plasmodium vivax malaria among sudanese children at New Halfa Hospital, Eastern Sudan. Parasites Vectors 2012, 5:154.

52. Brooker SLT, Kolaczinski K, Mohsen E, Mehboob N, Saleheen S, Khudonazarov J, Freeman T, Clements A, Rowland M, Kolaczinski J: Spatial Epidemiology of Plasmodium vivax, Afghanistan. Emerg Infect Dis 2006, 12(10):1600-1602. 
53. $\mathrm{MOH}$ : National Malaria Guidelines Third edtion. Addis Ababa: Federal Ministary of Health of Ethiopa; 2012.

54. Yewhalaw D, Wassie F, Steurbaut W, Spanoghe P, Van Bortel W, Denis L, Tessema DA, Getachew Y, Coosemans M, Duchateau L, Speybroeck N: Multiple insecticide resistance: an impediment to insecticide-based malaria vector control program. PLoS One 2011, 6(1):e16066.

55. Balkew M, Ibrahim M, Koekemoer LL, Brooke BD, Engers H, Aseffa A, Gebre-Michael T, Elhassen I: Insecticide resistance in Anopheles arabiensis (Diptera: Culicidae) from villages in central, northern and south west Ethiopia and detection of kdr mutation. Parasite Vectors 2010, 3:40

56. Nyarango PM, Gebremeskel T, Mebrahtu G, Mufunda J, Abdulmumini U, Ogbamariam A, Kosia A, Gebremichael A, Gunawardena D, Ghebrat Y, Okbaldet Y: A steep decline of malaria morbidity and mortality trends in Eritrea between 2000 and 2004: the effect of combination of control methods. Malar J 2006, 5:33.

57. Mmbando BP, Vestergaard LS, Kitua AY, Lemnge MM, Theander TG, Lusingu JP: A progressive declining in the burden of malaria in north-eastern Tanzania. Malar J 2010, 9:216.

58. Rose-Wood ADS, Traore B, Castro MC: Trends in malaria morbidity among health care-seeking children under age five in Mopti and Sevare, Mali between 1998 and 2006. Malar J 2010, 9:319.

59. Karema C, Aregawi MW, Rukundo A, Kabayiza A, Mulindahabi M, Fall IS, Gausi K, Williams RO, Lynch M, Cibulskis R, Fidele N, Nyemazi J-P, Ngamije D, Umulisa I, Newman R, Binagwaho A: Trends in malaria cases, hospital admissions and deaths following scale-up of anti-malarial interventions, 2000-2010, Rwanda. Malar J 2012, 11:236.

60. Masaninga F, Chanda E, Chanda-Kapata P, Hamainza B, Masendu HT, Kamuliwo M, Kapelwa W, Chimumbwa J, Govere J, Otten M, Fall IS, Babaniyi $\mathrm{O}$ : Review of the malaria epidemiology and trends in Zambia. Asian Pac J Trop Biomed 2013, 3(2):89-94.

61. Tambo E, Adedeji AA, Huang F, Chen J-H, Zhou S-S, Tang L-H: Scaling up impact of malaria control programmes: a tale of events in Sub-Saharan Africa and People's Republic of China. Infect Dis Poverty 2012, 1:7.

62. Cohen JM, Smith DL, Cotter C, Ward A, Yamey G, Sabot OJ, Moonen B: Malaria resurgence: a systematic review and assessment of its causes. Malar J 2012, 11:122

63. Jima D, Getachew A, Bilak H, Steketee RW, Emerson PM, Graves PM, Gebre $T$, Reithinger R, Hwang J: Malaria indicator survey 2007. Ethiopia: coverage and use of major malaria prevention and control interventions. Malar J 2010, 9:58.

64. MOH: National Strategic Plan for Going to Scale with Coverage and Utilization in Ethiopia, 2004 - 2007. Addis Ababa: Ministry of Health; 2004:1-29.

65. Negash K, Kebede A, Medhin A, Argaw D, Babaniyi O, Guintran JO, Delacollette C: Malaria epidemics in the highlands of Ethiopia. East Afr Med J 2005, 82(4):186-192.

66. Yolanda BL: The intersectoral response to the malaria epidemic in Ethiopia in 2003: an assessment. In The Global Malaria Crisis. Edited by Tong J. London: Overseas Development Institute; 2005:25-26.

\section{Submit your next manuscript to BioMed Central and take full advantage of:}

- Convenient online submission

- Thorough peer review

- No space constraints or color figure charges

- Immediate publication on acceptance

- Inclusion in PubMed, CAS, Scopus and Google Scholar

- Research which is freely available for redistribution 